\title{
Comparisons of self-determination among students with learning disabilities and without learning disabilities
}

\author{
Manijeh Shehni Yailagh ${ }^{1}$, Mohammad Abbasi ${ }^{2}$, Nasser Behrozi ${ }^{1}$, Sirus Alipour ${ }^{1}$, \\ Alireza Haji Yakhchali ${ }^{1}$ \\ ${ }^{1}$ Department of Educational Science and Psychology, Shahid Chamran Universitry of Ahvaz, Ahvaz, Iran \\ ${ }^{2}$ Department of Education, Shadegan Branch, Islamic Azad University, Khozestan, Iran \\ Email address: \\ abbasi.mohammad@hotmail.com (M. Abbasi)
}

\section{To cite this article:}

Manijeh Shehni Yailagh, Mohammad Abbasi, Nasser Behrozi, Sirus Alipour, Alireza Haji Yakhchali. Comparisons of Self-Determination among Students with Learning Disabilities and without Learning Disabilities. American Journal of Applied Psychology.

Vol. 3, No. 2, 2014, pp. 27-31. doi: 10.11648/j.ajap.20140302.11

\begin{abstract}
This study compared self-determination in 40 elementary school children with learning disabilities ) (sixth and fifth grade) and 40 their peers without LD. An ex post facto design was used. Statistical population comprised of all students in elementary schools (sixth and fifth grade) in, Ahwaz, Iran, during the 2013-2014 academic year. Students with learning disability were randomly selected. The students with LD had been diagnosed by Colorado Learning Difficulties Questionnaire (CLDQ). The student completed the Wechsler Memory scale and Self-Determination Student Scale (SDSS). Data were analyzed using analysis of variance. The Statistical Package for Social Sciences (SPSS 20) was used for computing descriptive statistics and multivariate analysis of variance (MANOVA). Differences were found between the groups on the self-determination.
\end{abstract}

Keywords: Self-Determination, Learning Disabilities, Iran

\section{Introduction}

Student with learning disabilities (LD) form the largest group of students with special educational needs in inclusive classrooms (Clark, \& Artiles, 2000). According to the International Statistical Classification of Diseases (2002), the basic learning disability is defined to emerge in reading, writing, and/or mathematics, even though the cognitive skills of these children are within normal range.

Research has identified a number of protective factors that help to foster resilience and well-being among kids with LD. People who have personal characteristics such as persistence in the face of adversity, flexibility to pursue alternate strategies when appropriate, and self-awareness are at reduced risk for problems. Further, Raskind, Goldberg, Higgins, \& Herman (1999) conducted a longitudinal study to determine predictors of success among individuals with LD. Forty-one adults with LD participated in interviews and cognitive and academic testing 20 years after they had left a treatment center for children with LD. Results indicated that the following attributes distinguished successful from unsuccessful adults: self-awareness, proactivity, perseverance, emotional stability, goal setting, and use of support systems.

On the other hand, self-determination has been postulated as a key skill set for students with LD (WhiteHector, 2012). Self-determination: "acting as the primary causal agent in one's life and making choices and decisions regarding one's quality of life free from undue external influence or interference" (Wehmeyer, 1996). Field, Martin, Miller, Ward, and Wehmeyer (1998) defined selfdetermination as self-disciplined behavior that involves goal making and other strengths. Understanding one's strengths as well as weaknesses but still being able to reach one's goals confidently and competently is true selfdetermination. As a result, one can become successful in adulthood.

Field and Hoffman (1994) developed a model of selfdetermination, as applied to persons with disabilities (Figure 1). The model Field and Hoffman (1994) proposed begins with knowing yourself and valuing yourself. This includes knowing strengths, weaknesses, needs and preferences, options and deciding what is important to you. Valuing yourself includes knowing your rights and responsibilities and taking care of you. When knowing and valuing yourself interact, the next thing that is possible is 
for the individual to plan. This includes setting goals, planning actions to meet those goals, and anticipating the results of one's actions. After planning, the next step is to act. To act means to take risks, communication, access resources and support, negotiate with others and be persistent. After acting, one will experience the outcomes and learn. Actual outcomes can be compared to expected outcomes, actual performance can be compared to expected performance, and success can be realized or adjustments can be made as necessary. As success or adjustments occur, this cycle starts again with knowing yourself and valuing yourself. In this way the authors posited that the actions interpreted as self-determination also produce more selfdetermined behavior.

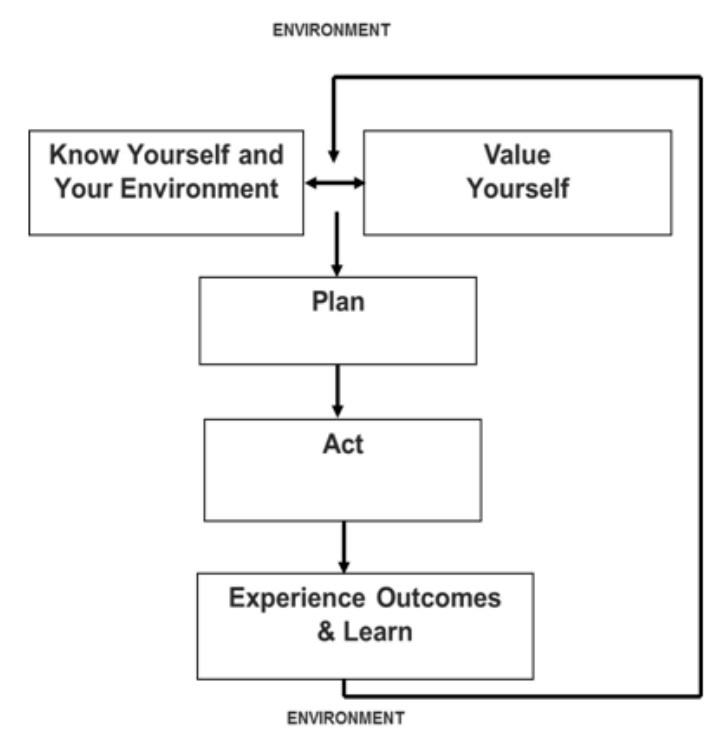

Figure 1. Model of Self-determination. From "Development of a Model for Self-Determination," by S. Field and A. Hoffman, 1994, Career Development for Exceptional Individuals, 17(2), p. 165.

Researchers found that persons with adequate selfdetermination skills accomplished more positive life experiences and lived a better quality of life than those who had better lives than people without self-determination skills (Wehmeyer \& Schwartz, 1997; Zhang, 2001). Wehmeyer, \& Garner (2003) found that students with disabilities meet more obstacles than those without disabilities in acquiring employment, housing, and engaging in their communities because they were not taught self-determination skills. Houchins (1998) found a positive correlation between scores on self-determination assessment and academic achievement scores for students who were incarcerated (jailed in juvenile detention). Sarver (2000) found a positive relationship between scores on selfdetermination assessment and grade point average for postsecondary students with learning disabilities.

Researchers found, Similarly, differences between the levels of self-determination of students with and without disabilities (Lipkowitz \& Mithaug, 2003; Mithaug, Campeau, \& Wolman, 2003; Shogren, Lopez, Wehmeyer, Little, \& Pressgrove, 2006).

\subsection{Purpose of Research}

This study compares children with LD and their peers without LD on self-determination (know yourself, value yourself, plan, act, and experience outcomes and learn). We hypothesized that children with LD would score lower on the self- determination than their peers without LD.

\subsection{Research Question}

Are there differences on self- determination (know yourself, value yourself, plan, act, and experience outcomes and learn) among Students with Learning Disabilities and without LD?

\section{Method}

\subsection{Participants and Procedures}

This study was a ex post facto design. Forty adolescents with LD (Forty boys, mean age 11.8 years) and forty male without LD (40 boys, mean 11.9 years) as a comparison group were recruited from elementary schools (sixth and fifth grade) in, Ahwaz, Iran. The students with LD had been diagnosed by Colorado Learning Difficulties Questionnaire (CLDQ) (21). Also, the diagnostic assessment included the Wechsler Intelligence Scale. Students with learning ability were randomly selected. The procedure for choosing the respondents involved 4 public elementary schools were randomly selected among the public elementary schools in, Ahwaz, Iran.

\subsection{Research Instruments}

Colorado Learning Difficulties Questionnaire (CLDQ) (Willcutt, Boada, Riddle, Chhabildas, DeFries, \& Pennington, 2011), a 20-item parent-report rating scale that was developed to provide a brief screening measure for learning difficulties. CLDQ ratings were obtained from parents of children. The CLDQ included 5 subscales: 1) Reading 2) Social cognition 3) Social anxiety 4) Spatial 5) Math. The validity and reliability of this test have been reported satisfactory in different. In this study, scale was carefully translated and corresponded to the main scale by the authors. Then, reliability was calculated. Results indicate that the scale has appropriate psychometric qualities to be used in Iran. The reliability of the test was .86 .

Wechsler Memory Scale: A primary instrument used in the present study was the measure of Wechsler memory which has been adapted to Iranian context and included 7 subscales: 1) information 2) orientation 3) mind control 4) arithmetic repeated the digits ahead 5) arithmetic repeated the digits reverse 6) total arithmetic digits and 7) visual memory. The validity and reliability of this test have been reported satisfactory in different researches. In this study, the reliability of the test was .93 .

Self-Determination Student Scale (SDSS): This 92-item measure was developed by Hoffman, Field, and 
Sawilowsky in 2004, based on Field and Hoffman's (1994) model of self-determination. This model contains five components: know yourself (16 items), value yourself (16 items), plan (19 items), act (25 items), and experience outcomes and learn (16 items). Each item is a statement participants answer as "That's me" or "That's not me." One such item is: "I can be successful even though I have weaknesses." The SDSS was normed on 251 youth ages 15-22, half of whom had disabilities, and found to be internally consistent and reliable with a Cronbach's alpha of .91 for the scale. For each subscale, the Cronbach's alpha was: know yourself (.70), value yourself (.13), plan (.66), act (.32), and experience outcomes and learn (.70). This measure, while developed for use with high school students, was used previously in a study with university students with LD (Sarver, 2000) and the scale reliability was roughly the same (.91) as compared to the consistency when normed. In this study, Self-Determination Scale was carefully translated and corresponded to the main scale by the authors. Then, to examine its validity, confirmatory factor analysis was carried out on its items and its reliability was calculated. Results indicate that the scale has appropriate psychometric qualities to be used in Iran. SDSS internal consistency reliability using Cronbach alpha was 0.79 for composite subscales.

\section{Results}

The data collected from the instruments will be entered into a computer file using SPSS. All inferential statistical analyses will use an alpha level of 0.05 . In this research, multivariate analysis of variance (MANOVA) was conducted to determine significant differences between students with learning disabilities and without LD on five dependent variables (know yourself, value yourself, plan, act, and experience outcomes and learn). One-way anova indicate that the scores are statistically significant (table 1).

Results revealed significant differences between students with learning disabilities and without LD, Pillais $\mathrm{F}(1,78)=$ $7.23, \mathrm{p}=<.05$. Univariate $\mathrm{F}$ values indicated that students with learning disabilities and without LD differed on know yourself, $\mathrm{F}(1,78)=24.92, \mathrm{p}<.001$, value yourself, $\mathrm{F}(1$, $78)=26.04, p<.001$, plan, $F(1,78)=14.53, p<.001$, act, $\mathrm{F}(1,78)=11.30, \mathrm{p}<.001$, and experience outcomes and learn, $\mathrm{F}(1,78)=9.63, \mathrm{p}<.001$. Specifically, students with learning disabilities felt less self-determination than students without LD. Means, standard and Results of OneWay MANOVA deviations for the different subscales are shown in Table 1.

Table 1. Results of One-Way MANOVA Comparison of Means on the self-determination for Students With and Without Learning Disabilities.

\begin{tabular}{|c|c|c|c|c|c|c|c|c|}
\hline \multicolumn{9}{|c|}{$\begin{array}{l}\text { Box's M tests }=16.96, p=>.05 \\
\text { Pillais } F(1,78)=7.23, p=<.05\end{array}$} \\
\hline & & \multirow{2}{*}{$\mathrm{N}$} & \multirow{2}{*}{ Mean } & \multirow{2}{*}{ Std. Deviation } & \multicolumn{2}{|c|}{ Levene's Test } & \multicolumn{2}{|c|}{ ANOVA } \\
\hline & & & & & $\mathrm{F}$ & Sig. & $\mathrm{F}$ & Sig. \\
\hline \multirow{2}{*}{ know yourself } & LD & 40 & 8.32 & 2.69 & \multirow{2}{*}{2.39} & \multirow{2}{*}{.126} & \multirow{2}{*}{24.92} & \multirow{2}{*}{.000} \\
\hline & NLD & 40 & 11.05 & 2.15 & & & & \\
\hline \multirow{2}{*}{ value yourself } & LD & 40 & 8.05 & 2.90 & \multirow{2}{*}{3.21} & \multirow{2}{*}{.077} & \multirow{2}{*}{26.04} & \multirow{2}{*}{.000} \\
\hline & NLD & 40 & 10.92 & 2.11 & & & & \\
\hline \multirow{2}{*}{ plan } & LD & 40 & 11.57 & 3.99 & \multirow{2}{*}{1.82} & \multirow{2}{*}{.181} & \multirow{2}{*}{14.53} & \multirow{2}{*}{.000} \\
\hline & NLD & 40 & 14.65 & 3.16 & & & & \\
\hline \multirow{2}{*}{ act } & LD & 40 & 13.22 & 5.21 & \multirow{2}{*}{0.19} & \multirow{2}{*}{.661} & \multirow{2}{*}{11.30} & \multirow{2}{*}{.001} \\
\hline & NLD & 40 & 16.92 & 4.21 & & & & \\
\hline \multirow{2}{*}{$\begin{array}{l}\text { experience outcomes } \\
\text { and learn }\end{array}$} & LD & 40 & 10.00 & 2.93 & \multirow{2}{*}{3.81} & \multirow{2}{*}{.055} & \multirow{2}{*}{9.63} & \multirow{2}{*}{.003} \\
\hline & NLD & 40 & 11.80 & 2.19 & & & & \\
\hline
\end{tabular}

\section{Discussion}

Students with LD typically experience more social, emotional, and motivational problems than students without LD (Ayres, Cooley, \& Dunn, 1990). Students with LD are often caught in a vicious spiral of school failure. Their learning difficulties lead to slower development of academic skills and abilities, which in turn impedes new learning (Stanovich, \& Matthew, 1996). As a result of the repeated cycle of failure, they fall farther and farther behind. Since learning differenced students tend to lower self-determination. Field and Hoffman
(1994) defined self-determination as, "the ability to identify and achieve goals based on a foundation of knowing and valuing oneself' (p. 174).

Self-determination is evidenced when a person knows his/her strengths and weaknesses, can plan actions, evaluate options, make and act upon decisions, and adjust as necessary during this process (Field \& Hoffman,1994; Malian \& Nevin, 2002). Self-determination is a critical set of skills which experts suggest has an influence on success at the college/university level and in adult environments (Brinckerhoff et al., 2002; Dukes \& Shaw, 2008; Field \& 
Hoffman, 2003; Eisenman, 2008).

The current study described and compared of SelfDetermination among Students with Learning Disabilities and without LD. Significant differences emerge in the selfdetermination between the two groups.

In summary, this research has indicated a distinctly lower level of self-determination for students with LD. These results are consistent with Raskind et al (1999), Mithaug, Campeau, \& Wolman (2003); and Shogren, Lopez, Wehmeyer, Little, \& Pressgrove (2006). All of whom found that the lower level of self-determination for students with LD. Further, the findings have important implications for both practice and future research. It is recommended that parents at least become familiar with importance selfdetermination for students with LD.

\section{Limitations}

It is important to consider the limitations of this study. The study was conducted on a relatively small sample, so generalization of results is limited.

Another limitation of this study was that, despite efforts to ensure that each participant responded to each item on the scales, there were occasional missing values. There are four ways to deal with missing data): a) eliminating the participant's data altogether, (b) replacing the missing data with the investigator's guess of a likely response, based on prior knowledge of how a given participant is likely to respond, (c) calculating the overall mean from the available data and replacing missing values with the mean across groups, or (d) inserting the group mean for a missing value (Tabachnick, \& Fidell, 1996). Rather than eliminating the entire set of responses from participants who omitted items, we chose to replace missing values with mean score.

\section{References}

[1] Ayres, R, Cooley E, \& Dunn C. (1990). Self-concept, attribution, and persistence in learning-disabled students. Journal of School Psychology; 28: 153-163.

[2] Brinckerhoff, L. C., McGuire, J. M., \& Shaw, S. F. (2002). Postsecondary education and transition for students with learning disabilities. Austin, TX: PRO-ED.

[3] Clark, M, Artiles, AA. (2000). Cross-National Study of Teachers' Attributional Patterns. The Journal of Special Education; 34(2): 77-89.

[4] Dukes III, L.L., \& Shaw, S.F. (2008). Using the AHEAD Program Standards and Performance Indicators to promote self-determination in the daily practice of the OSD. Journal of Postsecondary Education and Disability, 21(2), 105-108.

[5] Eisenman, L. (2007). Self-Determination Interventions Building a Foundation for School Completion. Remedial and Special Education, 28 (1), 2-8.

[6] Field, S., \& Hoffman, A. (2002). Lessons learned from implementing the Steps to Self- Determination curriculum. Remedial and Special Education 23, (2), 90-98.
[7] Field, S., \& Hoffman, A. (1994). Development of a model for self-determination. Career Development for Exceptional Individuals, 17, 159-169.

[8] Field, S., Hoffman, A., Sawilowsky, S. (2004). SelfDetermination Assessment Battery. Detroit, MI: Wayne State University.

[9] Field, S., Martin, J., Miller, R., Ward, M., \& Wehmeyer, M. (1998). A practical guide for teaching self-determination. Reston, VA: The Council for Exceptional Children.

[10] Houchins, D. E. (1998). The self-determination of youth with and without disabilities who have been adjudicated. Unpublished doctoral dissertation, University of Florida, Gainesville.

[11] International Statistical Classification of Diseases and Related Health Problems (10th Rev.). ICD-10: Third edition of the Finnish version of the International Statistical Classification of Diseases and Related Health Problems. StMichel Print; Mikkeli; 2011.

[12] Malian, I., \& Nevin, A. (2002). A review of selfdetermination literature: Implications for practitioners. Remedial and Special Education, 23, 68-74.

[13] Mithaug, D. E., Campeau, P. L., \& Wolman, J. M. (2003). Assessing self-determination prospects among students with and without disabilities. In D. E. Mithaug, D. K. Mithaug, M. Agran, J. E. Martin, \& M. L. Wehmeyer (Eds.), Self determined learning theory: Construction, verification, and evaluation (pp. 61-76). Mahwah, NJ: Lawrence Erlbaum.

[14] Raskind MH, Goldberg RJ, Higgins EL, \& Herman KL. (1999) Patterns of change and predictors of success in individuals with learning disabilities: Results from a twentyyear longitudinal study. Learning Disabilities Research \& Practice; 14: 35-49.

[15] Sarver, M. D. (2000). A study of the relationship between personal and environmental factors bearing on selfdetermination and the academic success of university students with learning disabilities. Unpublished doctoral dissertation, University of Florida, Gainesville.

[16] Shogren, K. A., Lopez, S. J., Wehmeyer, M. L., Little, T. D., \& Pressgrove, C. L. (2006). The role of positive psychology constructs in predicting life satisfaction in adolescents with and without cognitive disabilities: An exploratory study. The Journal of Positive Psychology, 1, 37-52.

[17] Stanovich K. Matthew. (1996). effects in reading: Some consequences of individual differences in the acquisition of literacy. Reading Research Quarterly; 21: 360-406.

[18] Tabachnick BG, \& Fidell LS. (1996). Using multivariate statistics (3rd ed.). New York: HarperCollins.

[19] Wehmeyer, M.L., \& Garner, N. W. (2003). The impact of personal characteristics of people with intellectual and developmental disability on selfdetermination and autonomous functioning. Journal of Applied Research in Intellectual Disabilities, 76, 255- 265.

[20] Wehmeyer, M. L., \& Schwartz, M. (1997). Selfdetermination and positive adult outcomes: A follow-up study of youth with mental retardation or learning disabilities. Exceptional Children, 63, 245-255. 
[21] Wehmeyer, M. L. Kelchner, K \& Richards, S. (1996). Essential characteristics of self-determined behaviors of adults with mental retardation and developmental disabilities. American Journal on Mental Retardation, 100, 632-642.

[22] White-Hector, A. (2012).The Effectiveness of the choice maker curriculum in increasing self-determination skills in high school special education students. Unpublished doctoral dissertation, University of Walden, Minnesota. Retrieved from ProQuest Dissertations \& Theses.
[23] Willcutt EG, Boada R, Riddle MW, (2011). Chhabildas N, DeFries J, \& Pennington BF. Colorado learning difficulties questionnaire: validation of a parent-report screening measure. Psychological Assessment. American Psychological Association; 23(3): 778-791.

[24] Zhang, D. (2001). The effect of next S.T.E.P. Instruction on the self-determination skills of high school students with learning disabilities. Career Development for Exceptional Individuals, 24, 121-132. 